\title{
Enfermería Nefrológica cumple todos los criterios de revista científica
}

\author{
Francisco Cirera-Segura
}

Vocal de Publicaciones de la Sociedad Española de Enfermería Nefrológica

En los últimos 3 años de trabajo de la actual junta Directiva de la SEDEN, se ha hecho una apuesta indiscutible por la calidad científica tanto de la revista Enfermería Nefrológica como de sus congresos. Un claro ejemplo es que Enfermería Nefrológica se ha convertido en un referente internacional y otro es la celebración del I Congreso Iberoamericano de Enfermería Nefrológica, que tendrá lugar en Madrid del 19 al 21 de noviembre de 2018.

A pesar de ello, el sistema actual de determinadas bolsas de trabajo pone en duda no ya la internacionalidad de la revista y sus publicaciones sino de su carácter científico, algo incuestionable a todas luces en el ámbito nacional e internacional. En cuanto al carácter científico, decir que somos una sociedad científica sin ánimo de lucroㅁ, cuyos objetivos son la investigación y la difusión del conocimiento sobre la enfermedad renal, así como a la formación de las enfermeras en el ámbito renal, formando parte como miembros de la UESCE (Unión Española de Sociedades Científicas de Enfermería).

Respecto a la internacionalidad de las revistas españolas, podemos afirmar que es un tema controvertido y objeto de discusión en los últimos años. Incluso el editor de la revista Nefrología, perteneciente a la Sociedad Española de Nefrología, publicó una editorial donde abordaba la internacionalidad de su revista fundamentando el cumplimento de determinados criterios internacionales ${ }^{2}$.

En un mundo interconectado mediante internet, la difusión del conocimiento científico ha ido adaptándose progresivamente a este mundo 2.0. Hemos visto como las publicaciones en papel se difunden mediante las bases de datos, revistas electrónicas, páginas web y redes sociales permitiendo su lectura en cualquier parte del mundo en cuestión de segundos. Otro elemento para tener en cuenta, es el acceso libre del conocimiento generado por los autores de la revista Enfermería Nefrológica, elemento clave para garantizar y facilitar la mayor difusión del conocimiento científico, firmando la declaración de Sant Joan d'Alacant en defensa del Acceso Abierto de las publicaciones científicas ${ }^{3}$ impulsado por el grupo de editores de las revistas españolas sobre ciencias de la salud (GERECS).

Podríamos pensar que la internacionalidad de cualquier revista se deba a que proceda del extranjero, que se publique en ingles o con aspectos relacionados con su comité editorial. En nuestro caso, queremos reafirmar el carácter internacional que tiene la revista Enfermería Nefrológica a pesar de que se edite en España.

En primer lugar, tenemos un comité editorial formado por miembros que residen en países diferentes. Además, es la publicación referente de la Sociedad Chilena de Enfermería en Diálisis y Trasplante Renal (SENFERDIALT), Sociedad de Enfermeras Especialistas en Nefrología del Perú (SEENP), la Sociedad Argentina de Enfermería Nefrológica (SAEN) y de la Associação Portuguesa de Enfermeiras de Diálise e Transplante (APEDT).

En segundo lugar, está el factor de impacto de las revistas. Enfermería Nefrológica está indexada en las principales bases de datos internacionales, como son CINHAL, IBECS, SCIELO, CUIDEN, SIIC, LATINDEX, DIALNET, DOAJ, EBSC0, DULCINEA, ENFISPO, SCOPUS/Scimago Journal Rank (SJR), Romeo, C17, Recolecta, Compludoc, Redalyc, Redib, Google Scholar Metric y Cuidatge, entre otras. Otro elemento a tener en cuenta es la métrica de la revista Enfermería Nefrológica ofrecida por Scimago Journal \& Country Rank (SJR), con un índice de 0,2 y situándose en el cuartil 3 de Advanced and Specialized Nursing en $2017^{4}$. Si nos fijamos en la métrica de CUIDEN citación $n^{5}$ la revista se sitúa en un cuartil 2 y un Repercusión inmediata de Cuiden (RIC) de 0,85.

Por tanto, el comité Editorial quiere manifestar y argumentar las siguientes razones que avalan el carácter científico de esta publicación: 
1. La revista Enfermería Nefrológica está incluida en los principales bases de datos internacionales, como son SCOPUS, CINAHL, CUIDEN, disponiendo de los indicadores que estas bases de datos aportan, como son el indicador RIC y SJR.

2. La revista Enfermería Nefrológica, es de acceso abierto, asegurando así la máxima difusión de las investigaciones que se publican en la misma.

3. La revista Enfermería Nefrológica admite manuscritos de cualquier país del mundo, escritos en inglés, español y portugués, lo que garantiza su difusión internacional a través de las bases de datos anteriormente mencionadas. La revista Enfermería Nefrológica es la publicación de referencia de hasta 5 sociedades científicas tanto de la península ibérica como de Latinoamérica, y en los últimos años está aumentado el porcentaje de autores de fuera de España que publican en esta revista.

4. La revista Enfermería Nefrológica cumple todos los criterios de las publicaciones científicas biomédicas exigidas por la FECYT, tanto los referentes a la composición del comité editorial, compuesto por profesionales referentes en el campo de la enfermería nefrológica a nivel internacional, como en los referentes al proceso editorial, incluido el proceso de revisión por pares.

Por todo lo anteriormente expuesto, podemos afirmar que Enfermería Nefrológica es la revista de referencia en el cuidado renal en el ámbito iberoamericano, formando parte de los canales globales de comunicación y con impacto en la ciencia internacional.

\section{Bibliografía}

1. Estatutos de la SEDEN. [Consultado 7 Agosto 2018]; Disponible en: https://www.seden.org//estatutos.

2. Rodríguez Portillo, M. Alcázar Arroyo R. Nefrología: una revista internacional. Nefrología. 2015; 35(2):125-6

3. Declaración de Sant Joan d'Alacant en defensa del Acceso Abierto a las publicaciones científicas del grupo de editores de revistas españolas sobre ciencias de la salud (GERECS). Enferm Nefrol 2017; 20(4):291-3. http://dx.doi.org/10.4321/S225428842017000400002.

4. Métricas SJR. [Consultado 7 Agosto 2018]; Disponible en: https://www.scimagojr.com/journalsearch. php $q q=21100416607 \&$ tip $=$ sid\&clean $=0$.

5. Métricas CUIDEN. [Consultado 7 Agosto 2018]; Disponible en: http://www.index-f.com/cuiden_cit/ citacion.php y http://www.index-f.com/bibliometria/ bresumen.php?id=424.

Este artículo se distribuye bajo una Licencia Creative Commons Atribución-NoComercial 4.0 Internacional. https://creativecommons.org/licenses/by-nc/4.0/ 